\title{
Weight and water loss in the neonate in natural and forced convection
}

\author{
M H THOMPSON, J K STOTHERS, AND N J McLELLAN \\ Neonatal Research Unit, London Hospital Medical College, London
}

SUMMARY We describe a simple method of determining weight loss and hence water loss of infants in incubators. Unlike previously reported methods, it does not interfere with the microenvironment surrounding the infant. Weight loss of 16 term and 32 preterm infants was measured in both forced and natural convection. No significant increase in water loss was observed in the term infants but in the preterm infants the mean loss in natural convection was $0.85 \mathrm{~g} / \mathrm{kg} /$ hour compared with $1.26 \mathrm{~g} / \mathrm{kg} /$ hour in forced convection: in the most extreme situation it was doubled. This water loss represents a substantial energy loss and suggestions to minimise it are discussed.

An infant lying in still air heats the surrounding air which then rises due to natural convection. The rate of rise is slow and the infant lies protected by an 'envelope' of heated air. To achieve a stable and uniform air temperature within the canopy in modern incubators, many manufacturers have employed fairly high circulating air velocities, some in excess of $20 \mathrm{~cm} / \mathrm{second}$. It has been shown, ${ }^{1}$ using a Schlieren optical system, that such air speeds destroy the natural convective pattern, creating 'forced convection'. The total heat loss of term infants nursed in forced and natural convection has been previously measured in a closed circuit metabolism chamber ${ }^{2}$ and found to be significantly increased under forced convection. The increase was due to a rise in dry heat loss rather than evaporative loss.

Preterm infants have higher rates of insensible water loss than those born at term. ${ }^{3}$ The resultant evaporative heat loss imposes considerable thermal stress on these infants, particularly those born before 32 weeks of gestation. The obvious difference in transepidermal water loss between term and preterm infants suggested that the latter, when exposed to forced convection, might have even greater losses than previously reported. The aim of this study was to investigate this possibility.

\section{Patients and methods}

Ūntil recently no system existed which could measure water loss in an incubator and which did not interfere with the macroenvironment created inside the canopy or the microenvironment surrounding the infant. For many years weight loss has been used as an index of water loss but traditional balances are either cumbersome, unstable, or environmentally intrusive. With the advent, however, of compact and highly accurate balances based on electromagnetic force compensation, these former problems can be overcome. ${ }^{4}$ One such machine is the Sartorius $3802 \mathrm{MP}$ which is relatively small yet weighs accurately to within $0 \cdot 1 \mathrm{~g}$ and has a range of $0-8000 \mathrm{~g}$. This was incorporated in the experimental equipment as shown in Fig. 1. To study weight loss at different air speeds, the fan motor of a Vickers's incubator (Model 79) was modified to produce circulating air velocities ranging from 5 to 25 $\mathrm{cm} /$ second, measured with a hot wire anemometer. The pattern of air flow within the canopy with the fan running at the normal speed of 20 to 25 $\mathrm{cm} / \mathrm{second}$ was visualised using Schlieren photography and found to be identical to that of an unmodified incubator. Details of the experiments performed to assess the accuracy of the weighing system are given in the Appendix.

Sixteen term and 32 preterm infants were measured in air velocities of 5 and $25 \mathrm{~cm} /$ second (Table 1). All the infants were well at the time of observation and were nursed prone and naked except for a small plastic urine bag. Informed parental consent was obtained. Minute by minute records of behavioural state using the criteria of Precht $1^{5}$ were made by an experienced observer continuously watching the infant. In several instances these records were checked against a con- 


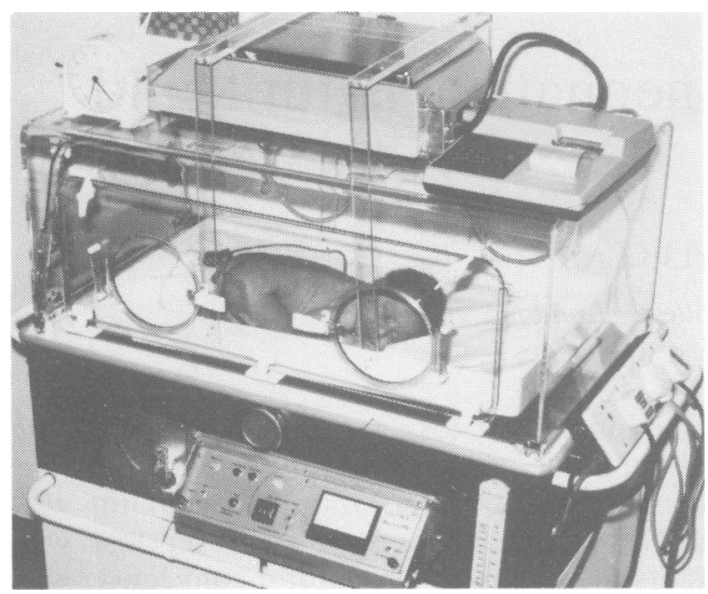

Fig. 1 The Sartorius balance on top of the incubator canopy.

Two perspex hoops run over the balance pan. through slots cut in the canopy and are attached to the tray inside the incubator.

tinuous electroencephalographic recording and were found to correlate well. Only periods of active sleep were included in the study, as quiet sleep was noted to be relatively uncommon and to be of short duration in the preterm infants. Any periods in which there was doubt regarding the infants' state were discarded.

The incubator temperature was set within the thermoneutral range, as defined by Hey and Katz. ${ }^{6}$ Four wall and air temperature recordings were made during the measurements to calculate the operative environmental temperature. ${ }^{7}$ The infants were all nursed in a relative humidity of between 20 and $40 \%$, recorded using an aspirating hydrometer. After the fan motor had been adjusted to give the desired air speed, the infant was placed on the incubator tray and at least 15 minutes allowed to elapse before measurement was begun. Rectal and skin temperatures were recorded either at the beginning and end of each study period or continuously. The rectal probe was inserted to a depth of five to seven $\mathrm{cm}$ and the skin thermistor attached to the lateral aspect of the upper arm, an area which most accurately reflects mean skin temperature changes. ${ }^{8}$

Weight loss was measured during the ensuing 20 to 30 minutes, readings being taken at five minute intervals under forced and natural convection. The values obtained were then regressed linearly against time to smooth the variations that arose as a result of the accuracy of the balance being limited to one decimal place. The weight loss in $\mathrm{g}$ /hour was calculated from the regression. Infants whose urine bag leaked, who dribbled excessively, or whose rectal temperature rose above $37 \cdot 3^{\circ} \mathrm{C}$ were excluded from the study. As explained in the Appendix, the water loss was calculated from the weight loss, assuming a respiratory quotient of 0.9 and an oxygen consumption of $7 \mathrm{ml} / \mathrm{kg} /$ minute for preterm infants and $6 \mathrm{ml} / \mathrm{kg} /$ minute for term infants.

\section{Results}

The weight losses in natural and forced convection in the term infants are shown in Table 2. When converted into water loss, the values were 0.57 and

Table 1 Details of term and preterm infants in the study

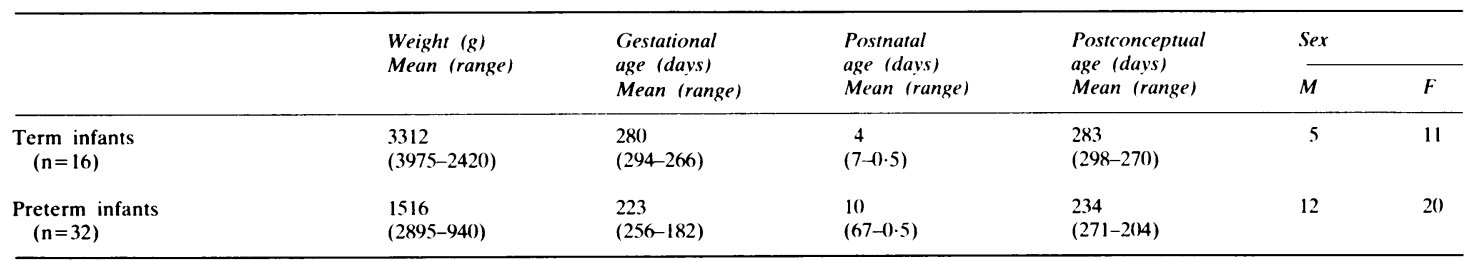

Table 2 Weight losses (mean (SD)) associated with natural and forced convection related to gestational age

\begin{tabular}{|c|c|c|c|c|c|c|}
\hline \multirow{2}{*}{$\begin{array}{l}\text { Gestational age } \\
\text { (weeks) }\end{array}$} & \multirow{2}{*}{$\begin{array}{l}\text { Postnatal age } \\
\text { (davs) }\end{array}$} & \multirow[t]{2}{*}{ No } & \multicolumn{2}{|c|}{ Weight loss $(\mathrm{g} / \mathrm{kg} / \mathrm{hour})$} & \multirow[t]{2}{*}{$P^{*}$} & \multirow[t]{2}{*}{$\%$ Increase } \\
\hline & & & Natural & Forced & & \\
\hline$<37$ & $>1$ & 32 & $1.01(0.29)$ & $1.39(0.47)$ & $<0 \cdot 01$ & 37 \\
\hline$<32$ & $<7$ & 8 & $1.22(0.29)$ & $1.83(0.36)$ & $<0.01$ & 50 \\
\hline$<30$ & $<7$ & 3 & $1 \cdot 17(0 \cdot 31)$ & $1.90(0.53)$ & - & 63 \\
\hline
\end{tabular}

*Wilcoxon matched pairs signed ranks test. 
$0.61 \mathrm{~g} / \mathrm{kg} /$ hour respectively. The mean difference of some seven per cent was not statistically significant, although 12 of the 16 lost more water in forced convection.

All but three of the 32 preterm infants had increased weight losses in forced convection (Fig. 2). This $37 \%$ difference (Table 2) was highly significant (paired Student's $t$ test $\mathrm{P}<0 \cdot 01$ ). Converted into water loss, the mean values were 0.85 and $1.26 \mathrm{~g} / \mathrm{kg} /$ hour respectively. In the case of the eight infants of less than 32 weeks' gestation and 7

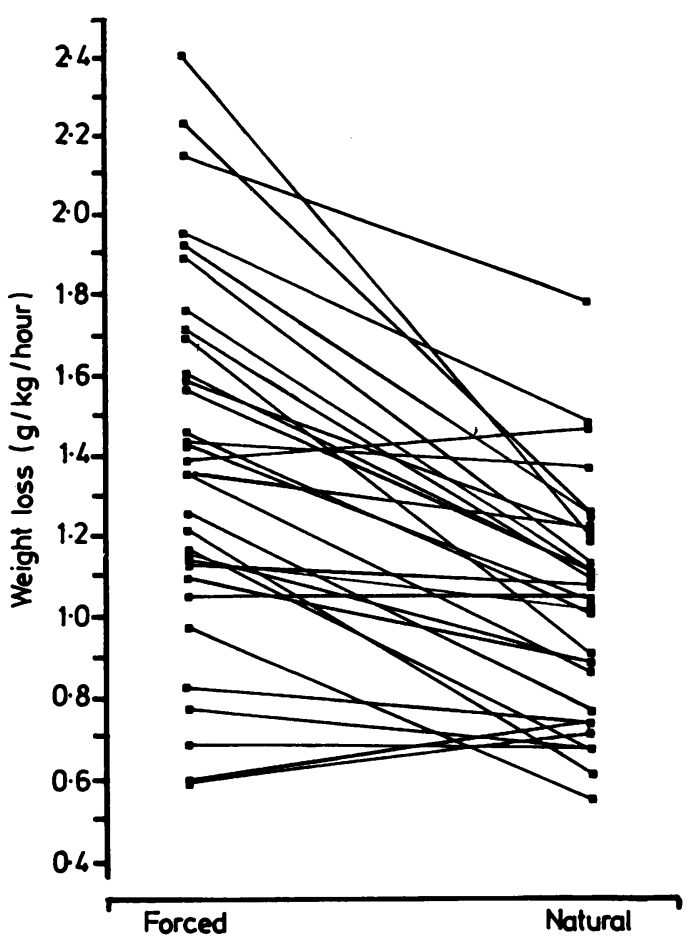

Fig. 2 Weight losses in the 32 preterm infants.

The range is large, to some extent reflecting the variation in ages of the infants when measured. days of age, the percentage rise associated with forced convection was $50 \%$ (Table 3 ), and in three infants of less than 30 weeks' gestation, this was $63 \%$. The maximal loss was observed in an infant of 28 weeks' gestation weighing $1020 \mathrm{~g}$. The measurements were made when the infant was about 20 hours old. In natural convection, his water loss was $1.18 \mathrm{~g} / \mathrm{kg} /$ hour, which more than doubled when the air speed was increased to $25 \mathrm{~cm} /$ second.

The gestational, postnatal, and therefore postconceptual ages varied over a wide range, especially in the preterm infants. To take account of these variables, linear regressions of each of them against the logarithmic values of the weight loss in all 48 infants were performed with the values obtained in both natural and forced convection. Logarithmic values of the weight loss were used as previous work $^{3}$ suggests that the relation between water loss and age is not linear. Statistical comparisons of the slopes of each pair of regressions were then carried out. It can be seen (Table 3) that there was a significant relation between gestational and postconceptual ages and weight loss and a significant difference between the slopes calculated from the natural and forced convective data. From the present results there seems to be no simple relation between postnatal age and weight loss, although there was a large variation between the infants. The postconceptual age regressed against weight loss provided the strongest correlation of those performed. Converting this into water loss provides the data points and regression lines shown in Fig. 3. The regression lines are of the log of the water loss plotted using the original units. It is interesting to note that the lines intersect shortly after term.

Multiple regression analysis was also performed with weight loss as the dependent variable and postconceptual age and air speed being independent. Resultant multiple regression was found to be significant at the one per cent level $(F=44$, degrees of freedom 2, 93). The exact mathematical relation was:

Weight loss $=3 \cdot 08+(0 \cdot 01$ postconceptual age $)$

Table 3 Values of the linear regressions of postnatal, gestational, and postconceptual ages against the log of weight loss in both natural and forced convection in all 48 infants studied

\begin{tabular}{|c|c|c|c|c|c|c|c|c|}
\hline & \multicolumn{4}{|c|}{ Natural convection } & \multicolumn{4}{|c|}{ Forced convection } \\
\hline & $A$ & $B$ & $r$ & $P$ & $A$ & $B$ & $r$ & $P$ \\
\hline Postconceptual age* & 0.625 & 0.0027 & -0.562 & $<0.01$ & $1 \cdot 396$ & -0.0054 & -0.791 & $<0 \cdot 01$ \\
\hline Gestational age* & 0.465 & 0.0022 & -0.512 & $<0.01$ & $1 \cdot 115$ & $-0 \cdot(0) 45$ & -0.746 & $<0 \cdot 01$ \\
\hline Postnatal age & $0 \cdot 069$ & 0.0004 & 0.045 & NS & 0.014 & $0 \cdot 0017$ & $0 \cdot 121$ & NS \\
\hline
\end{tabular}

Values are shown in the conventional form of $y=A+B x$, where $y$ is the log of the weight loss in $g / k g / h o u r, ~ x$ is the age in days. $A$ is the intercept. and $B$ is the slope of the regression line.

* Statistical comparison of the slopes in natural and forced convection show a significant difference. 


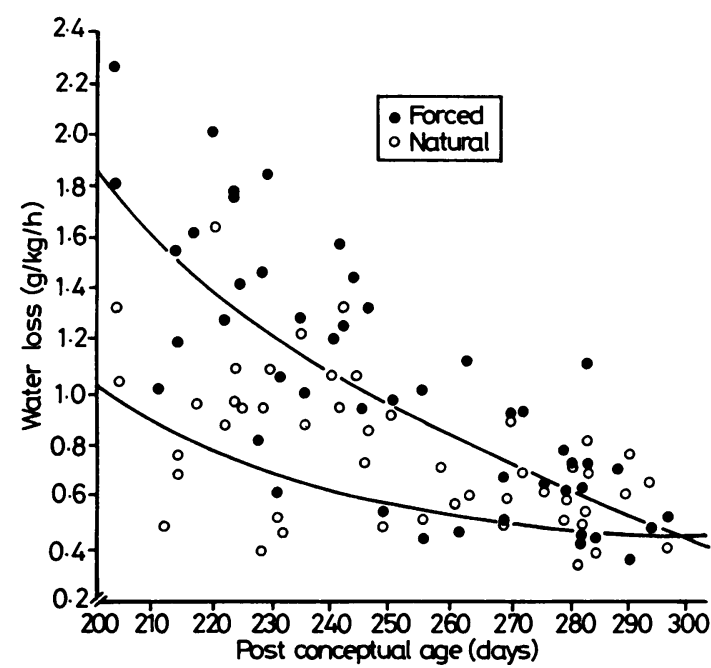

Fig. 3 Water losses plotted against postconceptual age in both natural and forced convection.

Differences tend to lessen with postconceptual age. the axes of the two regression lines crossing at 290 days.

$+(0.03$ air speed $)$ where weight loss is in $\mathrm{g} / \mathrm{kg} /$ hour postconceptual age in days, and air speed in $\mathrm{cm} / \mathrm{second}$.

From this formula it can be calculated that on the first day of life an infant born at a gestational age of 28 weeks will lose $1.67 \mathrm{~g} / \mathrm{kg} /$ hour when nursed in an air speed of $20 \mathrm{~cm} / \mathrm{second}$. This can be reduced to $1.25 \mathrm{~g} / \mathrm{kg} /$ hour by lowering the air speed to about 5 $\mathrm{cm} / \mathrm{second}$.

\section{Discussion}

The calculated water losses of the term infants nursed in air speeds of less than $5 \mathrm{~cm} / \mathrm{second}$ were very similar to those reported by Hey and Katz ${ }^{9}$ and Sulyok et al. ${ }^{10}$ The losses in their series were measured directly by subtracting the water content of the air before and after passing over the infant in a metabolism chamber. The water loss measured using this method, therefore, includes both skin and respiratory tract losses. Measurements of skin water loss alone using the 'evaporimeter' method described by Nilsson ${ }^{11}$ have shown greater variation $\left(0.73 \mathrm{~g} / \mathrm{kg} /\right.$ hour, Nilsson; ${ }^{11} 0.53 \mathrm{~g} / \mathrm{kg} /$ hour, Rutter; ${ }^{3}$ and $0 \cdot 25 \mathrm{~g} / \mathrm{kg} /$ hour, Hammarlund $\left.^{12}\right)$. Using Hey's ${ }^{9}$ values of the water content and temperature of expired air, a respiratory water loss of $0.2 \mathrm{~g} / \mathrm{kg} /$ hour might be expected. This must be added to the values of skin water loss if total values are to be compared.
The reason for the variations in those authors' results is not obvious but the air speeds at which the measurements were carried out were different, being about $15 \mathrm{~cm} / \mathrm{second}$ in Nilsson's series ${ }^{11}$ and $25 \mathrm{~cm} / \mathrm{second}$ in Rutter's. ${ }^{3}$ In addition, the effect of air speed on the performance of the evaporimeter readings is not known.

It is known that the resistance of the air to diffusion of water is much less than that of the skin which it surrounds. ${ }^{13}$ Skin resistance is generally attributed to the keratin content of the stratum corneum which is present in greater quantities in the term infant than the preterm. The superficial layer of the preterm infant's skin is higher in water content ${ }^{14}$ and therefore presents a 'wetter' surface to the moving air, with a resultant increase in evaporative loss.

The mean weight loss in preterm infants measured in natural convection by Okken, ${ }^{15}$ using a complex weighing system, was $1.67 \mathrm{~g} / \mathrm{kg} /$ hour compared with $1.01 \mathrm{~g} / \mathrm{kg} /$ hour in the present series. There are two main reasons for this $40 \%$ difference: firstly, the larger number of very immature infants with naturally high water loss in Okken's series, and secondly, the fact that his infants were nursed in a net hammock, thereby presenting virtually the entire surface area of each infant for evaporative loss. In the present study the infants were measured lying prone on a firm mattress, the area exposed being lessened therefore by up to $30 \% .{ }^{16}$ The mean value of $1.26 \mathrm{~g} / \mathrm{kg} /$ hour would be increased to 1.69 $\mathrm{g} / \mathrm{kg} / \mathrm{hour}$ if the postural effect were taken into account.

The mean increase of $37 \%$ in water loss in forced convection is of obvious clinical importance. An evaporative loss of $1 \mathrm{~g} /$ hour represents a heat loss of $2.48 \mathrm{kj} /$ hour and not simply replaceable water lost. In energy terms, assuming a maximum energy intake of $504 \mathrm{kj} / \mathrm{day}$ the increase in evaporative heat loss in forced convection would demand $20 \%$ of the total energy intake. In addition to evaporative loss, the infant also loses heat by radiation and convection-conduction and work being negligible. Forced convection in term infants has been shown to increase the dry heat losses by some $15 \%{ }^{2}$ The degree of this loss is inversely proportional to the diameter of the body exposed and is probably greater in preterm infants, as their overall diameters are much less than those born at term. The actual energy losses associated with water loss in forced and natural convection have been calculated from the data obtained from a 1 day old infant weighing $2.1 \mathrm{~kg}$ and are shown in Fig. 4.

Lowering the air speed within the canopy is one obvious solution to the problem but this would require major redesign of the incubator to maintain 


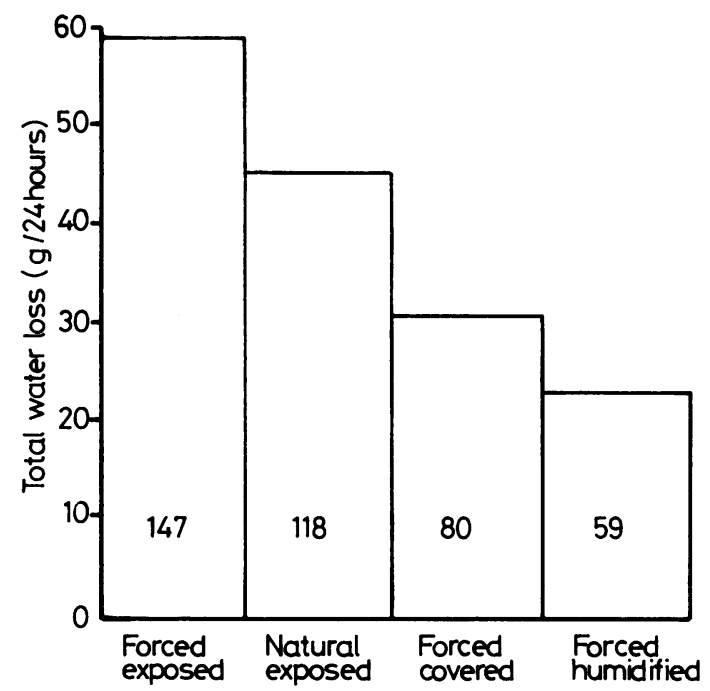

Fig. 4 Calculated water losses of a $2100 \mathrm{~g}$ infant, whose weight loss was measured during the second day of life.

Environmental temperature in the unhumidified runs was mean (SD) $32 \cdot 2$ $(0 \cdot 2)^{\circ} \mathrm{C}$ and the relative humidity $37 \%$ (water content of air: $11.0 \mathrm{mg} / 1$ ). The relative humidity in the incubator was raised to $65 \%$ at the same environmental temperature, raising the water content to $24.0 \mathrm{mg} / \mathrm{l}$. The inserted numbers represent the evaporative heat loss in $\mathrm{kj} /$ hour.

thermal stability. Alternatively, one might attempt to reduce dry heat losses by a heated canopy or by providing radiant heat. Unfortunately, the first is an extremely expensive undertaking and the second might exaggerate the problems of fluid balance frequently encountered in preterm infants. More traditional methods of overcoming water loss in small infants include covering the infant with a non-permeable plastic sheet or humidifying the atmosphere inside the incubator. The relative efficacy of each can also be seen in Fig. 4. The drawback of the first method is that the plastic sheet is removed periodically and immediately the water loss will increase. Some time will elapse after the sheet is replaced before the humidity beneath it will increase to 'protective' levels. There are few disadvantages of humidifying the incubator, the main one being that Pseudomonas aeruginosa may be isolated from the water reservoir. In units at present using humidification to combat high transepidermal water loss in small preterm infants, however, little trouble has been experienced from the latter (Hey and Rutter, personal communications), especially if care is exercised in cleaning the incubator and the incubator is run 'dry' for one hour in 24. We therefore strongly support the humidification of incubators in the first week or so of life in preterm infants whose energy expenditure may exceed maximum heat production.

\section{Appendix on methods}

Before the main study a series of measurements were made to assess the accuracy of the weight loss measurements and to permit these to be converted to water loss with reasonable accuracy. In this series the weight loss measured using the gravimetric balance was compared with water loss values obtained during periods of observation in the closed circuit metabolism chamber, during which time the oxygen consumption was also being measured. It should be noted that before using the balance measurements the whole system was run for several hours to ensure that there was no 'extraneous' weight change due to heating effects on the balance or the mattress.

The gestational ages of the 13 infants included in this study ranged from 29 to 40 weeks and their postnatal ages from 1 to 67 days. Their mean weight was $2800 \mathrm{~g}$, ranging from 1360 to $3735 \mathrm{~g}$. From these infants a total of 22 paired observations were obtained, 11 in forced and 11 in natural convective situations. As described in the main Methods section, the babies were all nursed prone and naked except for a small plastic urine bag. Comparing the results using paired $t$ test, showed the difference to be $0.44 \mathrm{~g} /$ hour which was significant $(\mathrm{P}>0 \cdot 01)$.

Weight loss $(\mathrm{WtL})$ is related to water loss $(\mathrm{WL})$ by the equation:

$$
\mathrm{WtL}=\mathrm{WL}+\mathrm{wCO}_{2}-\mathrm{wO}_{2}
$$

where $\mathrm{wCO}_{2}$ and $\mathrm{wO}_{2}$ are the weights of the expired carbon dioxide and inspired oxygen respectively. If a respiratory quotient is assumed, the value of expired carbon dioxide, and therefore its weight, can be calculated from the measured oxygen consumption. The weight of one litre of carbon dioxide is $1.965 \mathrm{~g}$ and that of one litre of oxygen is $1.429 \mathrm{~g}$ at standard temperature and pressure, dry. The respiratory quotient during the neonatal period has been variously estimated as lying between 0.85 and 0.95 , obviously depending upon substrate nature and availability. By assuming a respiratory quotient of $0 \cdot 9$, the mean difference between the corrected chamber weight loss and the measured loss was reduced to $0.08 \mathrm{~g} /$ hour ( $\mathrm{P}>0.05$ ), the actual values (Fig. 5) being $2.29 \mathrm{~g} /$ hour for the chamber calculated loss and 2.37 g/hour for the measured loss.

In converting the incubator weight loss into water loss, the reverse calculation must be made and to do this the oxygen consumption must be assumed. In the small series described above, the oxygen consumption (at standard temperature and pressure, dry) of the preterm infants was mean (SD) $7.2(1.06) \mathrm{ml} / \mathrm{kg} /$ minute and that of the term infants was $6.3(0.42) \mathrm{ml} / \mathrm{kg} / \mathrm{minute}$. These values are approximately 7 and $6 \mathrm{ml} / \mathrm{kg} /$ minute respectively and are in good agreement with those obtained by other workers.

Any potential errors in these assumed values for oxygen consumption are not large. In the case of the preterm infants a difference of $1 \mathrm{ml} / \mathrm{kg} /$ minute would result in a difference of about only $3 \%$ in the calculated water loss and somewhat less in the case of those born at term. 


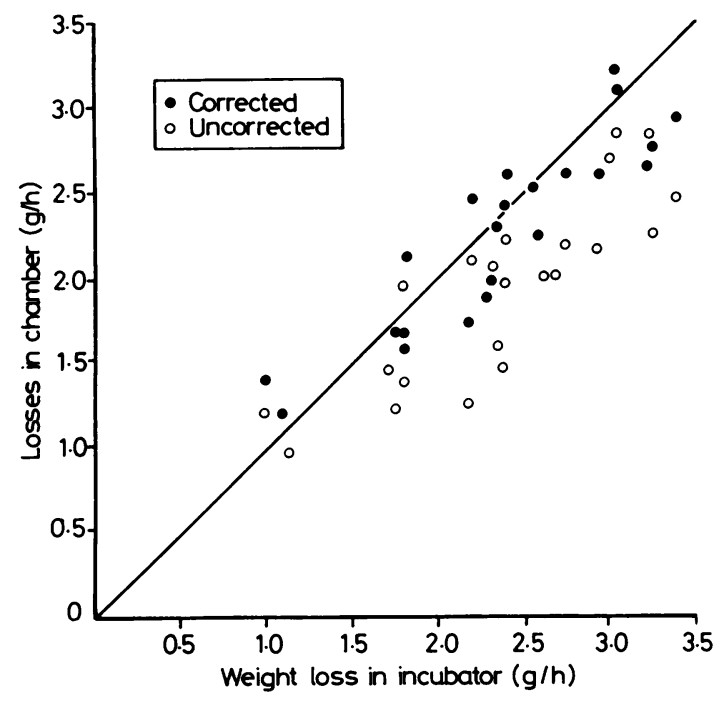

Fig. 5 Uncorrected values of weight loss and corrected values which take into account oxygen consumption and respiratory quotient.

All but two of the uncorrected values lic below the line of identity

We thank Professor K W Cross and Dr M K S Hathorn for encouragement, Miss Ruth Warner for nursing assistance, and Mrs Irene Sampson for help in preparing the manuscript. Thanks are also due to the parents of the infants measured for permission to do so, and to the medical and nursing staff of the obstetric wards and the Neonatal Intensive Care Unit of The London Hospital for cooperation. The project was funded by the Medical Research Council. The Wellcome Trust, and Sartorius Ltd.

\section{References}

' Clark RP, Cross KW, Goff MR, Mullen BJ, Stothers JK, Warner RM. Neonatal natural and forced convection. J Physiol 1978;284:22-3P.
2 Stothers JK. The effect of forced convection on neonatal heat loss. J Physiol 1980;305:77P.

${ }^{3}$ Rutter N. Hull D. Water loss from the skin of term and preterm babies. Arch Dis Child 1979;54:858-68.

+ Stothers JK. Thompson MH, Wade AJ, Warner RM. A system for measuring neonatal weight loss in incubators. J Physiol 1981;313:2-3P.

${ }^{5}$ Prechtl HFR. The neurological examination of the full-term newborn infant. Clinics in Developmental Medicine No 63, 2nd edition. London: Heinemann, 1977:12.

${ }^{6}$ Hey EN. Katz G. The optimum thermal environment for naked babics. Arch Dis Child 1979:45:328-34.

${ }^{7}$ Gagge AP. Standard operative temperature, a generalized temperature scale applicable to direct and partitional calorimetry. Am J Physiol 1940):131:93-103.

* Clark RP, Stothers JK. Neonatal skin temperature distribution using infra-red colour thermography. J Physiol 1980;302: 323-33.

${ }^{9}$ Hey EN, Katz G. Evaporative water loss in the newborn baby. J Physiol 1969;200:605-19.

10 Sulyok E, Jéquier E. Ryser G. Effect of relative humidity on thermal balance of the newborn infant. Biol Neonate 1972;21:219-28.

11 Nilsson GE. On the measurement of evaporative water loss. Linköping University Medical Dissertations No 48 1977;1-3, III-4.

12 Hammarlund K. Sedin G. Strömberg B. Transepidermal water loss in newborn infants. Acta Paediatr Scand 1983;72:1-7.

${ }^{13}$ Kerslake D McK. The stress of hot environments. Monographs of the physiological society No 29. Cambridge: Cambridge University Press, 1972:122.

14 Rutter N, Hull D. Reduction of skin water loss in the newborn. I. Effect of applying topical agents. Arch Dis Child 1981;56: $669-72$.

15 Okken A, Jonxis JH, Rispens P, Zulstra WC. Insensible water loss and metabolic rate in low birthweight newborn infants. Pediatr Res 1979;13:1072-5.

16 Stothers JK. Indirect measurement of the output of heat from the brain of the human newborn. London: University of London PhD thesis. 1979;100.

Correspondence to Dr J K Stothers, The Neonatal Research Unit, The London Hospital Medical College, Turner Street. London E1 2AD.

Received 11 May 1984 